\title{
The Case of the Common Law in European Legal Education
}

Professor Avrom Sherr, Institute of Advanced Legal Studies, University of London, England

The journey across the Channel Tunnel may not be far, but the distance that divides systems based on the Napoleonic code from the precedential basis of the Common Law is considerable. The Common Law countries of Europe suffer an extra set of difficulties in relation to European Legal Education. Not only do they need to contemplate, consider and discuss the development, integration and harmonisation of European law (issues which other European countries face); they have the additional difficulty of absorbing the approach of a different juridical family and legal culture. The adjustment involved in trying to keep up with massive political change in the growing coverage of the European Union is exacerbated by the absence of a set of shared assumptions that exist between jurisdictions from the same juridical family. The UK can seriously wonder whether the Common Law approach will have a long term future in Europe, or whether it will be subsumed within the Civil Law culture of its European colleagues.

But, the European context is not the only operating factor. Europe itself must do business internationally and with multi-national companies. The importance of the United States of America in international trade and the effect this will have on modes of transaction and legal culture should not be ignored. Americanisation includes a strengthening of Common Law approach and practice. The nature of this effect though, may not be politically channelled through the Common Law members of the European Union, but will be felt across all countries, through transactional rather than political impetus. But, in the same way that the effect of the United States constitution was to be transported strongly through interstate trade rather than politics in the early days of American federalism, the power of commerce may still prove stronger than that of policy.

So, what may be learned from the case of the Common Law in European legal education, given this background? This essay will concentrate on three issues:

The English and Welsh model of legal education, training and qualification.

The impact of the Common Law/ Civil Law families divide on European law and legal education.

The impact of changing legal professions and professionalism on future legal education across Europe.

Although the collection of these items ranges across a wide set of issues, each issue may be instructed in terms of the Common Law tradition and its place in European legal education.

"Il Modello Inglese"

In an essay published by the Faculty of Law at the University of Genoa in 1996 I elucidated the theoretical division between two traditional approaches to legal 
education, the apprenticeship model and the educational model, as two different models of professional "formation".

Apprenticeship Model Educational Model

Practice Theory

Reality Concepts and Ideas

Sitting at the feet of... Abstraction

Inheriting the mantle of the Priesthood A formative period

The assumptions which underlie each of the above models are fairly clear. However, the reality of legal education turns out to be very different. Apprenticeship is supposed to provide a full understanding of what is involved in legal practice. As a system of training the new profession it ought to give, like a set of courses in a formalised training structure, a full range of understanding of the world of practice. However, the venues in which apprenticeship takes place both for solicitors and barristers in England and Wales are now heavily specialised firms and chambers with little capacity to provide the full range of real practice which would be an ideal introduction to the law. Solicitors' practices which provide apprenticeship training (the training contract) are largely orientated towards company and commercial work, or are involved in the high street work of conveyancing and legal aid family and crime. There is now very little crossover between these two groupings. Training in practice now therefore means training in a very particular sort of specialised practice. The ability of lawyers to move to other areas of practice at a later date is considerably undermined by this massively specialised form of training.

The type of firms and chambers who are prepared to take on trainees are also usually quite special. They need to be large enough to support the new bureaucracy of the training contract and they will also as a result, be quite involved in managing their practices as a business enterprise, with a level of standardisation of work in order to provide efficiency. The management of a business enterprise does not always go well, hand in hand, with effective training. Some trainees complain of being overworked in some repetitive task areas. Some complain of long hours and a strong expectation to pull their weight as money earners from the beginning.

Apprenticeship is also supposed to provide reality, as compared with a more formal educational approach, dealing with clients and others directly and the vicissitudes of real life. However, trainees in large organisations are often kept at some distance from clients. Their work is devolved down to them and deskilled. They often do not understand the nature of transactions or litigation in which they are involved, because the tasks they carry out and the role they fulfil are such a small part only of the whole process.

In the traditional model of the apprenticeship relationship, the apprentice would "sit at the feet of" his or her "master" or "mistress" who would initiate the apprentice into the secrets of the trade. They would be imbued with the fire of experience and they would receive, individually, the professional tradition on a one-to-one basis. Now, in order to 
avoid the uncertainties of a poor apprenticeship, the system of training is much more formalised. There is rarely an individual to individual relationship. Trainees move from "seat" to "seat" in different departments of a larger enterprise and they miss out on the fire of enthusiasm which could be handed from generation to generation in the old system. They would also traditionally have inherited "the mantle of the priesthood" and then moved into the position of their "master" when their master retired or died. The liklihood of job inheritance is now quite small. Although, in some firms they do intend to take on trainees who will move into partnership, this progression is much more of a corporate style of movement than an individualistic right of passage. Nowadays, it is unlikely that apprenticeship in any occupation can be considered to be a job for life.

Over in the Educational model is the system of formation which is more usually to be found as the exclusive model both in parts of Europe, and in the United States. The assumptions underlying this model are that it presents a stronger, more basic, theoretical approach to the study of law. Unfortunately, in England, we find our undergraduate programme to include increasingly "black letter" law, providing considerable amounts of doctrinal information to be learned and regurgitated. The subjects are often limited to a fairly narrow "core" which is partly dictated by the profession. There is little jurisprudence in the sense of "legal theory" and very little comparative law. There is very little study of the system and how it works or of any higher theory or social science doctrine. In some subjects, where the pressure of more and more material has been greatest, teachers have been forced to analyse their subject area more into concepts and ideas rather than sheer knowledge. But, often this conceptualisation has not occurred. Courses tend to be so packed with cases and statutes that there is little time within the three years of the undergraduate law degree for abstract thought and reflection. In general the examination method still applies and the form of the examination tends to dictate the method of teaching and the approach and culture of the students.

The three years within formal education is intended to provide a formative period for students, during which they can develop both emotionally and intellectually. This issue is especially important in relation to their ethical and moral development. But, our students do not now treat this period in any idealised fashion. They consider the degree merely to be a stepping stone to take them forward to their goal. Examination results are therefore the only outcomes which matter.

Apart from changes in the social culture of education generally and legal education in particular, there have been both regulatory and bureaucratic changes in the systems for monitoring education in England, Wales and Scotland. The Higher Education Funding Councils organise a Research Assessment Exercise ("RAE") and the Quality Assurance Agency for Higher Education organises an assessment of the quality of teaching and teaching systems. Both of these have the tendency towards the formalisation and standardisation of research and teaching approaches.

Coupled with the Institute for Teaching and Learning in Higher Education, these will produce an important advantage in relation to higher education establishments which previously fell below the norm. However, there are serious negative effects also possible for those establishments which did not previously need bureaucratic intervention or formalisation in order to achieve, or operate at, a high standard in 
relation both to research and teaching. Such interventions are clearly aimed at a mass system of higher education, organised to include institutions and students which would not previously have considered degree status. In general, law degree authorised institutions have tended to deal with faculty and staff motivated towards objectives beyond the mere label of an undergraduate degree. Disciplines such as law and medicine may benefit less from these interventions than others. But, the effect of such educational policy will be felt across all sectors and disciplines.

The largest changes within legal education for the profession have occurred at an even later stage through the development of vocational professional courses, formal elements of training within apprenticeship (as mentioned above) and the Continuing Professional Development ("CPD") of lifelong learning.

In summary, the informality and variability of apprenticeship is considerably controlled within a structured and formalised system for solicitors, although less so for barristers, and this reduces some of the major advantages of an apprentice system. However, it does strengthen individual areas of poor performance within that system which would otherwise have fallen below an acceptable norm. The educational model is now perceived by students and utilised by society more pragmatically than as a stage of development and maturity. It is a product-orientated period aiming to achieve the narrower objectives of securing a qualification, and preparing students for some elements of practice. Formalisation and bureaucratisation of higher education are also beginning to standardise legal education. This may raise the standard of lower achieving institutions but will limit diversity. The Common Law approach to legal education can therefore provide some interesting comparison for the rest of Europe. As we move to harmonisation of qualifications such issues will need careful attention.

Common Law at the suit of Civil Law or the harmonisation of the two

The educational aspects of handling European law may be separated from the issues relating to the distinctions between national legal systems and the new law of Europe. But, for the common law countries there is a separate and much greater problem of the harmonisation, merger, or take-over of common law jurisprudence by the civil law jurisprudence of most countries in Europe. Although this is seen as the problem of England, Wales, Scotland and Ireland it is undoubtedly a problem, in relation to harmonisation, for the other European countries to contend with, as well.

This raises a much considered but undecided set of issues about the precise distinctions between the civil and common law. It is an issue with theoretical, political, sociological and economic, as well as legal, dimensions. It is very much a "big issue" which has vexed jurists for some time. Many, including in particular Mirjan Damaska, have endeavoured to explain the fundamental differences in the two systems, approaches, philosophies, cultures and histories etc. It seems clear that the overall comparisons defy a simplistic analysis on an intellectual plain. The politics of Europe are rather more obvious, but they still defy rational solutions as can be seen in the negotiation processes involved in agreeing all the major treaties of the Common Market, European Economic Community and European Union. Although the politics may be more obvious, they are less certain in their outcome. 
With an uncertain intellectual base, and a set of unclear political results, it is difficult to know how to handle the legal educational aspects of the Common Law - Civil Law divide. Europe has done rather well in producing the Erasmus and Socrates programmes, providing both student and faculty exchanges across the members of the European Union. Professor Fenge's work (in this same volume) provides interesting evidence of the degree of awareness of European issues, involvement in European exchange and study of European law. This author's own intuitive research among students who have come across from mainland Europe on these programmes, or English students who have gone to other countries in Europe suggests that this method of exchange may not be sufficient by itself to produce the necessary analysis of distinctions between Common Law and Civil Law systems. Such students, and indeed staff, who have been involved in such exchanges, note only the complexity of the comparisons between the different systems. Although we have therefore produced a small group of exchange students and staff who are to some extent "super Europeans" with some real understanding of both Civil and Common Law approaches, ultimate analysis of fundamental difference which intellectually will be necessary for real harmonisation still defies easy achievement.

It is suggested that, like the inbreeding of the evolutionary process, more widespread integration will be achieved through continuing this dual learning approach. But integration and true harmonisation are quite different processes with a rather different outcome. The two systems may continue to live happily side by side, but European law will have a more long term effect on trying to bring them closer together.

The disciplines of comparative law and the insights they allow is somehow not sufficient for the fast moving process of Europeanisation. Comparativists are tested quite strongly by the political nature of this process and what can be achieved in unpicking differences over a short period of time.

One recent instance, showing the complexity of any analysis relates to the effect of the European Money Laundering Directive on legal professions across Europe. The Law Societies of the Common Law jurisdictions of Europe, England and Wales, Scotland and Ireland signed up to the Money Laundering Directive, incorporating into their own ethical rules of conduct a total obedience to the aims of the Money Laundering Directive, which were then largely pointed at banks and other financial institutions. It would appear that these presented "a good example" of public interest in fighting crime.

The position taken by the Common Law jurisdictions contrasts strongly with the opposite position taken by most of the Civil Law countries of Europe, apart from the Netherlands. Most Civil Law countries considered the principles of lawyer client confidentiality and of privilege to be essential elements in championing liberty against the shadow of the over powerful state.

This position appeared to be a stark contrast and difficult discussions were held in Brussels on how to harmonise the total opposition of principle. However, on a closer inspection of the reality of practice it became clear that legal professionals in the Common Law countries were not in fact reporting their clients, or even potential clients to the National Criminal Investigation Service where there was any question of money laundering, or doubts about the identity of potential clients or of the 
provenance of funds. In the Common Law tradition, although the rules were clearly stated in the rule book they were politely, if hypocritically, ignored and ways were found around the reporting obligations which appeared to be present. In reality therefore the differences of principle turned out to be similarities of practice, thus proving that any work in this area must consider a number of different levels, both of reality and of principle in producing a complete analysis of where differences occur and where problems arise.

Changes in the legal professions of Common Law Europe and the effect of these changes on legal education

Borrowing, as they do, from the experience of the United States, the Common Law legal professions of Europe have been ahead of the Civil Law jurisdictions in changes in structure, organisation, work, specialisation. These changes can be summarised as a move towards industrialisation and deprofessionalisation. These professional changes ought to change considerably the structure, nature and education and training needs of the legal professions of the future.

Elsewhere I have discussed the effect of these changes on current work practices. It is now necessary to consider how legal education and training should, or should not match up to the new paradigms of legal work. If legal education should react to the new legal profession and not serve its own, or separate, interests, how should legal education and training be organised for the future? Some possible changes in career paths for lawyers and in legal subject areas within the Common Law system need also to be addressed.

Among the new legal careers emerging are the "back office" drafts person, information officer/professional support lawyer, specialist technician, advocate, manager, client handler/manager/partner, strategist, risk manager. In addition for Common Law lawyers there may be some new legal concepts as subject classifications. These include relative need, risk, right, relationship, responsibility, remedy and quality of life. There may also be some new legal subject classifications including the State, the individual, the family, the corporate body, the trust, the environment, capacity, conflict. Although many of these are similar to areas of legal work currently covered, the argument is that the new classification will overall present a rather different picture for the evolution of both legal practice and legal education. Some of these areas are already better recognisable within Civil Law jurisdictions than within the Common Law, but some other elements may need further consideration as to how the impact of the changes in the law and the legal profession will be taken up within legal education.

\section{Conclusion}

The member countries of the European Union need a continuing, open awareness to differences in approach in legal education as well as in law of other member countries. There is a great deal we can still learn from each other. Student, teacher and practitioner exchange schemes are essential elements of this progressive development. Changes occur outside of the European Union context which will impact on the profession and legal education. These also must continue to be monitored so that we can understand and plan for the future in circumstances of growing harmonisation. 